Eskişehir Osmangazi Üniversitesi iißBF Dergisi

Aralık 2020, C. 15, S. 3, 1081- 1094

Başvuru : : 19.12.2019

Kabul : : 17.04.2020

\title{
Banka Sermayesi Şokları ve Kredi Büyümesi: Türk Bankacılık Sektörü
}

\author{
Taner Sekmen ${ }^{1}$
}

Banka Sermayesi Şokları ve Kredi Büyümesi: Türk Bankacılık Sektörü

Öz

$\mathrm{Bu}$ çalışma banka sermayesine ilişkin düzenlemelerin kredi dalgalanmaları üzerindeki etkilerini sorgulamaktadır. Çalışmada bankaların sermaye oranlarının Türk bankacılık sektörünün kredi arzı üzerindeki etkilerinin banka düzeyindeki veriler ile panel VAR ekonometrik yöntemleri kullanılarak incelenmesi, Türkiye için meseleyi bu çerçevede ele alan ilk teşebbüs olması bakımından önemlidir. Türkiye'de faaliyet gösteren 26 yerli ve yabancı bankaya ait, 2002Q4 ve 2019Q2 dönemini kapsayan veriler ile yapılan analizlerden elde edilen bulgular sermaye yeterliliklerinin sıkılaştırılmasının bankacılık sektörünün kredi arzı üzerinde anlamlı negatif etkilere sahip olduğunu göstermektedir. Bulgular sermaye yeterlilikleri üzerindeki düzenlemelerin, bankaların kredi arzını kontrol amaçı politika uygulamalarının planlanmasında önem taşıyabileceğini ima etmektedir. Genel olarak konjonktürel sermaye yeterlilikleri ve sermaye tamponları gibi makro ihtiyati politika araçlarının Türkiye'de kredi dalgalanmalarını dolayısıyla da finansal dalgalanmaları düzleştirmede kullanılabileceği sonucuna varılmaktadır.

Anahtar Kelimeler: Sermaye Yeterlilikleri, Kredi Dalgalanmaları, Panel VAR, Makro İhtiyati Politikalar
Bank Capital Shocks and Credit Growth: Turkish Banking Sector

Abstract

This study investigates the impacts of bank capital regulations on credit cycles. In the study, the investigation of the effects of banks' capital ratios on the loan supply of the Turkish banking sector with bank-level data and panel VAR econometric methods is important as it is the first attempt to address the issue within this framework for Turkey. The findings obtained from the analysis with data covering the period from 2002Q4 to 2019Q2 and 26 domestic and foreign-owned banks operated in Turkey show that tightening capital requirements have a significant negative effect on the loan supply of the banking sector. The results of the study imply that regulations on capital requirements may be important in planning policy practices to control banks' loan supply. Overall, it can be concluded that macro-prudential policy tools such as countercyclical capital requirements and countercyclical capital buffers may be used to smooth the credit cycle and, thus, financial cycles in Turkey.

Keywords: Capital Requirements, Credit Cycles, Panel VAR, Macro-Prudential Policies

\section{Giriş}

Finansal piyasalar ya da finansal sistem son otuz yılda muazzam bir gelişme kaydetmiştir. Öyle ki özellikle uluslararası sermaye akışındaki artışlar ve finansal piyasaların birbirine hızlı entegrasyonu, finansal ürün ve kurum çeşitliliği gibi gelişmeleri içeren bu süreç başta gelişmekte olan ülkeler olmak üzere diğer tüm ülkelerde yatırımlar ve dolayısıyla iktisadi büyüme için gereken fon kaynaklarının sağlanmasına katkıda bulunarak bu dönemde iktisadi büyümenin en önemli itici gücü olmuştur. Ancak finansal gelişme ve iktisadi büyüme arasında kurulan bu güçlü ilişki finansal piyasalarda yaşanan aksaklıkların eskiye göre daha hızlı ve daha yıpratıcı bir biçimde ülke ekonomilerine aktarılmasına yol açmaktadır. Finansal piyasalardaki sorunların yarattığı diğer bir problem ise uluslararası iktisadi ve finansal entegrasyonunun boyutu dolayısıyla olumsuz etkilerin hızla diğer ülkelere yayılmasıdır. Bu anlamda en çarpıcı tecrübe yaşanan 2008 küresel finansal krizi olarak karşımıza çıkmaktadır. Finansal sistemde yaşanan tüm bu gelişmeler ve tecrübeler makroekonomik istikrarın sağlanabilmesi için finansal istikrarın sağlanması gerek-

\footnotetext{
${ }^{1}$ Dr. Öğr. Üyesi, Eskişehir Osmangazi Üniversitesi iiBF iktisat Bölümü, tsekmen@ogu.edu.tr, Yazar ORCID bilgisi: https://orcid.org/0000-0002-0363-3765
} 
liliği ve dolayısıyla finansal sistemin bu amaç doğrultusunda regüle edilmesini gerekli kılmaktadır. Finansal sistemin ve bu sistemin en önemli unsuru olan bankacılık sisteminin regüle edilmesine ilişkin görüşler son yıllarda daha fazla tartışılmasına rağmen bu çerçevedeki uluslararası düzenlemeler finansal gelişme sürecine paralel bir seyir izlemiştir. Bu anlamda 1988 yılında Basel I çerçevesinde uluslararası bankacılık düzenlemeleri ile başlayan bu süreç günümüzde de devam etmektedir. 2010 yılındaki Basel III düzenlemeleri çerçevesinde ise sermaye yeterlilikleri ve sermaye tamponları gibi bankaların sermaye yapısına ilişkin düzenlemelerin konjonktürel olması önerilmektedir. Bunun yanı sıra farklı risk unsurlarını içeren farklı sermaye oranlarına ilişkin yeterlilikler belirlenmektedir. Şüphesiz bu düzenlemelerdeki amaç bankacılık sisteminin özellikle de kredi piyasalarının istikrarıdır. Bu düzenlemelerle birlikte kredi dalgalanmalarındaki azalmaların beraberinde ekonomik aktivitedeki dalgalanmaları da azaltarak makroekonomik istikrarı sağlaması beklenmektedir.

Bankaların sermaye yapısına ilişkin düzenlemeler son yıllarda ülkelerin makroekonomi politikalarının önemli bir parçası haline gelmektedir. Özellikle 2008-2009 küresel finansal krizi sırasında bankalar ve finansal kurumların varlıklarında yaşanan sert kayıplar bu kurumların sermaye yapısında bozulmalara yol açarak bankaların sermaye yapısına ilişkin düzenlemelerin önemini daha da belirginleştirmiştir. Bu çerçevede yeni bir makro ihtiyati politika aracı olarak kullanılan sermaye yeterliliklerinin konjonktüre göre ayarlanması, iktisadi genişleme dönemlerinde bankaların sermaye yeterliliklerinin artırılarak kredi genişlemesindeki artışları yavaşlatmak ve bu yüksek sermaye düzeyinin ekonominin daralma dönemlerinde bankaların varlık tarafında ortaya çıkabilecek bozulmalar karşısında kullanılması olarak görülmektedir. Politika tarafında bu uygulamalar kullanılıyor olmasına rağmen sermaye yapısına ilişkin sermaye yeterlilik oranları ya da sermaye tamponları gibi politika araçlarının potansiyel etkilerinin anlaşılması gerekmektedir. Burada akla gelen en temel soru bankaların sermayelerinde ya da sermayelerinin varlıklarına oranında meydana gelen dalgalanmalar karşısında kredilerini nasıl ya da ne yönde ayarlayarak tepki verdikleridir. Bu sorunun cevabı teorik ${ }^{2}$ ve ampirik olarak net değildir.

Banka sermayesinin banka kredilerini nasıl etkileyeceği hakkındaki teorik ve ampirik literatürün çoğu Modigliani ve Miller (1958) teoreminin standart varsayımlarını esneterek hareket etmektedir (Hancock ve Wilcox, 1994; Berger ve Udell, 1994; Peek ve Rosengren, 1995; Van den Heuvel, 2002; Gambacorta ve Mistrulli, 2004; Nier ve Zicchino, 2005; Berrospide ve Edge, 2010). Modigliani ve Miller teorisinin sonuçlarını genel olarak ifade edersek eğer sermaye piyasalarında tam rekabet koşulları geçerli ise bankalar kredi verme fırsatlarını finanse edebilmek için öz kaynak ya da borçlanma ile fon sağlayabilir. Her zaman borçlanmadan daha maliyetli olan öz kaynak finansmanı oranındaki bir artış hem borçların hem de öz kaynağın birim maliyetindeki azalış tarafından tam olarak dengelenecektir. Bu koşullar altında fonların içinde öz kaynağın payının kredi arzı üzerinde bir etkisi olmamaktadır. Diğer bir ifadeyle bir bankanın sermaye yapısı bankanın değeri ve fonlama maliyetiyle ilişkisizdir (Gambacorta ve Mistrulli, 2004; Elliott, 2009; Francis ve Osborne, 2012; Labonne ve Lamé, 2014). Ancak teorinin bu önermesi idealize edilmiş koşullar altında geçerli olmaktadır. Gerçek dünyada ise vergiler, mevduat sigortası ve asimetrik bilgi problemlerinin varlığı sermaye piyasalarında aksak rekabet ya da piyasa kusurlarının oluşmasının temel nedenleri olarak görülebilir. Tüm bu olası faktörlerin ortaya çıkması teorinin bu sonucunu geçersiz kılmakta ve bankanın sermaye yapısı ile krediler arasında

\footnotetext{
2 Sermaye yapısına ilişkin düzenlemelerin banka davranışlarına etkisi konusunda kapsamlı bir teorik literatür taraması için VanHoose, D. (2007) çalışması incelenebilir.
} 
bir ilişki olabileceği sonucunu doğurmaktadır (Dewatripont ve Tirole, 1994; Elliott, 2009; Labonne ve Lamé, 2014). Bu teorinin diğer bir önermesi ise öz kaynak maliyetinin kaldıraç oranı ile birlikte arttığı şeklinde ifade edilebilir. Her iki önerme de geçersiz ise bankanın sermaye yapısı içinde öz kaynaklardaki bir artış, bankayı mevduat veya toptan fonlama gibi daha ucuz finansmandan mahrum bırakacak ve dolayısıyla kredilerde bir azalmaya yol açabilecektir. Ancak vergiler ve asimetrik bilgi gibi piyasa kusurlarının var olduğu daha gerçekçi bir çerçeve birinci önermede olduğu gibi ikinci önermenin de geçersiz olmasını gerekli kılmamaktadır. Örneğin; bu piyasa kusurları olsun olmasın kaldıraç oranındaki artış ile birlikte öz kaynak maliyeti de artacaktır. Çünkü bankanın riski artacak ve dolayısıyla bankaya fon sağlayan yatırımcılar bu riski telafi etmek için daha yüksek getiri arayacaktır. Dolayısıyla sermaye içinde öz kaynakların payında bir artış öz kaynakların marjinal maliyetini düşürecektir. Bu koşullarda ise daha fazla sermayenin krediler üzerindeki etkisi belli değildir (Labonne ve Lamé, 2014).

Bankaların sermaye oranlarının, varlıkları ve dolayısıyla kredileri üzerindeki etkisine teorik olarak daha farklı cevaplar verilebilir. Sermaye kayıplarından kaynaklı olarak bankanın sermaye oranında bir azalmanın olduğu durumda banka varlıklarında dolayısıyla banka kredilerinde hiçbir değişme olmayabilir. Çünkü bankanın mevcut sermaye oranı ya da düzenleyici otoritenin belirlediği oran banka açısından bağlayıcı olmayabilir. Diğer bir ifadeyle banka sermaye kaybı sonrasında bile iyi bir sermaye yapısına sahip olabilir (Berrospide ve Edge, 2010). Diğer bir olası durumda ise eğer bankalar Adrian ve Shin'in (2010) vurguladığı gibi sabit bir kaldıraç oranı ya da sermaye yeterlilik oranı sürdürme eğiliminde ise (ya da düzenleyici otorite tarafından zorlanıyorlar ise) sermayelerini artırma yeteneği sınırlı olabilir. Bu koşullarda sabit sermaye yeterlilik oranı, varlıklarda ve dolayısıyla kredilerde bir azalma ile sağlanabilecektir. Ancak sermayeyi artırmak diğer fon sağlama türlerine göre genellikle maliyetli olduğundan bankaların varlıklarını ve dolayısıyla kredilerini azaltması daha olasıdır.

Banka sermaye oranın banka kredileri üzerindeki etkisinin ne olduğuna yönelik teorik tartışmaların devam etmesi bu ilişkiyi ampirik bir soru olarak karşımıza çıkarmaktadır. Bu çalışma banka sermayesinde ortaya çıkan şoklar karşısında banka kredilerinin nasıl tepki verdiği şeklindeki mevcut tartışmaya Türkiye verileri ile ampirik olarak katkı sağlamayı amaçlamaktadır. Elde edilen bilgiler çerçevesinde bu çalışma Türkiye'de bankacılık sektörü düzeyindeki verilerle bu soruya cevap arayan ilk teşebbüs olması bakımından önemlidir. Banka sermayesi ve kredi arzı ilişkisi 26 bankaya ait 2002-2019 yılları arasını kapsayan çeyrek dönemlik veriler ve panel veri vektör otoregresif model (Panel VAR) yöntemi kullanılarak incelenmektedir.

Çalışmanın devamı dört bölümden oluşmaktadır. İkinci bölüm banka sermayesi ve kredi arzı literatürünü özetlemektedir. Üçüncü bölümde kullanılan veriler ve yöntem tanıtılmaktadır. Dördüncü bölümde ekonometrik tahminler ve bulgular yer alırken beşinci ve son bölüm ise çalışmanın sonucu ve politika önerilerine ayrılmaktadır.

\section{Literatür Taraması}

Bankanın sermaye yapısının banka kredileri üzerindeki etkileri 1988 yılında Basel I kapsamında ortaya konulan ilk düzenlemelerden itibaren araştırılmasına rağmen son finansal krizin ardından tüm ülkelerde finansal sistem özellikle de bankalara ilişkin regülasyon temelli makro intiyati tedbirlere yönelik politikalardaki artışlar bu konudaki araştırmaların artmasına yol açmıştır. Bu konuda geniş bir literatür olmasına ve politika yapıcıların bu uygulamaları aktif olarak kullanmasına rağmen banka sermayesinin krediler üzerindeki etkilerinin ne olduğu sorusuna verilen ampirik cevaplar bir fikir birliği sağlamaktan yoksundur. 


\section{Eskişehir Osmangazi Üniversitesi IïB Dergisi}

Ampirik literatür genel olarak değerlendirildiğinde çalışmaların temel olarak üç farklı kategoride yoğunlaştığı söylenebilir. Bunların ilki kredi arzı ve kredi talebi arasındaki ayrımı vurgulamaya yönelik olan çalışmalardır. Bu gruptaki çalışmalar diğer makroekonomik koşullarda ortaya çıkan değişmeler karşısında oluşan kredi talebi değişimlerinin kredi arzı üzerindeki etkisini, banka sermayesinin kredi arzı üzerindeki etkisinden ayırt etmeye çalışmaktadır.

Tablo 1. Literatürde Yer Alan Son Dönem Çalışmalar

\begin{tabular}{|c|c|c|c|}
\hline Çalışma & Örneklem & Yöntem & Sonuçlar \\
\hline $\begin{array}{l}\text { Gambacorta ve Mist- } \\
\text { rulli (2004) }\end{array}$ & $\begin{array}{l}\text { 1992:Q3 2001:Q3 } \\
\text { İtalyan bankaları }\end{array}$ & $\begin{array}{l}\text { Panel Veri Sabit } \\
\text { Etkiler } \\
\text { GMM }\end{array}$ & $\begin{array}{l}\text { Güçlü sermayeye sahip bankalar para politikası } \\
\text { ve GSYiH şokları karşısında kredilerini daha iyi } \\
\text { korurlar }\end{array}$ \\
\hline Elliott (2009) & - & $\begin{array}{l}\text { Modifiye edilmiş } \\
\text { Modigliani-Miller } \\
\text { analizi } \\
\text { Hassaslık Analizi }\end{array}$ & Pozitif etki tespit edilmektedir. \\
\hline $\begin{array}{l}\text { Berrospide ve Edge } \\
\text { (2010) }\end{array}$ & $\begin{array}{l}\text { 1992:Q1 2009:Q3 } \\
\text { 165 Banka } \\
\text { ABD }\end{array}$ & $\begin{array}{l}\text { Panel Regresyon } \\
\text { VAR }\end{array}$ & $\begin{array}{l}\text { Sınırlı pozitif etki vardır ve VAR modelinde etki } \\
\text { daha büyüktür. }\end{array}$ \\
\hline $\begin{array}{l}\text { Tabak, Noronha ve Ca- } \\
\text { jueiro (2011) }\end{array}$ & $\begin{array}{l}\text { 2000-2010 çeyreklik } \\
\text { dengesiz panel veri } \\
134 \text { Banka } \\
\text { Brezilya }\end{array}$ & $\begin{array}{l}\text { Feasible Genera- } \\
\text { lized Least } \\
\text { Squares (FGLS) }\end{array}$ & $\begin{array}{l}\text { Resesyon sermaye tamponunu artıır ve kredi } \\
\text { genişlemesi azalır. }\end{array}$ \\
\hline $\begin{array}{l}\text { Drehmann ve Gamba- } \\
\text { corta (2012) }\end{array}$ & $\begin{array}{l}\text { 1998:Q1-2009:Q4 } \\
\text { 772 Banka } \\
\text { ABD ve Avrupa Birliği } \\
\text { Ülkeleri }\end{array}$ & $\begin{array}{l}\text { Simülasyon Yön- } \\
\text { temleri } \\
\text { Panel GMM }\end{array}$ & $\begin{array}{l}\text { Konjonktür karşıtı sermaye tamponları ekono- } \\
\text { mik genişleme dönemlerinde kredi genişleme- } \\
\text { sini azaltabilir. }\end{array}$ \\
\hline $\begin{array}{l}\text { Francis ve Osborne } \\
(2012)\end{array}$ & $\begin{array}{l}\text { 1996-2007 Çeyreklik } \\
\text { veri } \\
\text { İngiltere bankaları }\end{array}$ & $\begin{array}{l}\text { Panel Veri Sabit } \\
\text { Etkiler }\end{array}$ & $\begin{array}{l}\text { Sermaye yeterlilik oranları arzulanan sermayeyi } \\
\text { etkileyerek sermaye miktarı ve kredilerde ayar- } \\
\text { lamalara neden olur. }\end{array}$ \\
\hline $\begin{array}{l}\text { Maurin ve Toivanen } \\
\text { (2012) }\end{array}$ & $\begin{array}{l}\text { 2005:Q1-2011:Q4 } \\
51 \text { Banka } \\
\text { Almanya, Fransa, } \\
\text { İtalya, İspanya,Belçika, } \\
\text { Avusturya, Portekiz }\end{array}$ & $\begin{array}{l}\text { Panel Veri Sabit } \\
\text { Etkiler } \\
\text { GMM }\end{array}$ & $\begin{array}{l}\text { Yetersiz sermayeye sahip bankaların ekono- } \\
\text { miye kredi aktarmalarında kısıtlamalar olmak- } \\
\text { tadır. }\end{array}$ \\
\hline Mora ve Logan (2012) & $\begin{array}{l}\text { 1990-2004 altı aylık ve- } \\
\text { riler } \\
139 \text { banka } \\
\text { Birleşik Krallık }\end{array}$ & $\begin{array}{l}\text { Panel VAR } \\
\text { Panel Veri Sabit } \\
\text { Etkiler } \\
\text { GMM }\end{array}$ & $\begin{array}{l}\text { Banka sermayesindeki bir düşüş finansal olma- } \\
\text { yan özel şirketlere sağlanan kredileri azaltırken } \\
\text { hane halklarına verilen kredileri artırmaktadır. }\end{array}$ \\
\hline $\begin{array}{l}\text { Berger ve Bouwman } \\
\text { (2013) }\end{array}$ & $\begin{array}{l}\text { 1984:Q1 ve 2010:Q4 } \\
\text { 60589 banka }\end{array}$ & $\begin{array}{l}\text { Logit Regresyon } \\
\text { OLS }\end{array}$ & $\begin{array}{l}\text { Sermaye küçük bankaların hayatta kalmasını ve } \\
\text { piyasa payını artırmasına yardımcıdır ve orta ve } \\
\text { büyük bankaların kriz dönemlerinde perfor- } \\
\text { mansının artmasını sağlar. }\end{array}$ \\
\hline $\begin{array}{l}\text { Carlson, Shan ve Wa- } \\
\text { rusawitharana (2013) }\end{array}$ & $\begin{array}{l}2001-2011 \\
3000 \text { banka }\end{array}$ & MSA Sabit Etkiler & $\begin{array}{l}\text { Son kriz döneminde sermaye oranları ve kredi- } \\
\text { ler arasında anlamlı bir ilişki tespit edilmiştir. } \\
\text { Sermaye oranı daha düşük bankalar için kredi- } \\
\text { lerin, sermaye oranlarına göre esnekliği göreli } \\
\text { olarak daha yüksektir. }\end{array}$ \\
\hline $\begin{array}{l}\text { Aiyar, Calomiris } \\
\text { ve Wieladek (2014) }\end{array}$ & $\begin{array}{l}\text { 1998-2007 çeyreklik } \\
\text { veriler } \\
277 \text { banka } \\
\text { Birleşik Krallık }\end{array}$ & Panel Regresyon & $\begin{array}{l}\text { Sermaye yeterliliklerindeki değişiklikler düzen- } \\
\text { lemeye tabi olan bankaların kredi arzını etkile- } \\
\text { mektedir; fakat düzenlemeye tabi olmayan } \\
\text { bankalar ise bu açığı dengelemektedir. }\end{array}$ \\
\hline $\begin{array}{l}\text { Labonne ve Lame } \\
\text { (2014) }\end{array}$ & $\begin{array}{l}\text { 2003:Q1 - 2011:Q4 } \\
13 \text { banka } \\
\text { Fransa }\end{array}$ & $\begin{array}{l}\text { Panel Veri Sabit } \\
\text { Etkiler }\end{array}$ & $\begin{array}{l}\text { Daha fazla sermaye daha fazla kredi vermeye } \\
\text { yardımcı olmaktadır. Kredilerin sermaye oran- } \\
\text { larına esnekliği ise daha fazla denetime sahip } \\
\text { olan bankalar için daha düşüktür. }\end{array}$ \\
\hline $\begin{array}{l}\text { Karmakar ve Mok } \\
\text { (2015) }\end{array}$ & $\begin{array}{l}\text { 1996:Q1 - 2010:Q4 } \\
\text { ABD bankaları }\end{array}$ & $\begin{array}{l}\text { Panel Veri Sabit } \\
\text { Etkiler } \\
\text { Araç Değişken } \\
\text { Regresyon }\end{array}$ & $\begin{array}{l}\text { Banka sermayesi ve krediler arasında ılımlı bir } \\
\text { ilişki vardır. }\end{array}$ \\
\hline
\end{tabular}




\begin{tabular}{|c|c|c|c|}
\hline $\begin{array}{l}\text { Košak, Li, Lončarski ve } \\
\text { Marinč (2015) }\end{array}$ & $\begin{array}{l}2000-2010 \\
4106 \text { banka }\end{array}$ & $\begin{array}{l}\text { Panel Veri Sabit } \\
\text { Etkiler } \\
\text { Araç Değişken } \\
\text { Regresyon }\end{array}$ & $\begin{array}{l}\text { Kaliteli bir banka sermayesi, kriz dönemlerinde } \\
\text { banka kredilerinin sürdürülebilmesi için son de- } \\
\text { rece önemlidir. }\end{array}$ \\
\hline $\begin{array}{l}\text { Osborne, Fuertes ve } \\
\text { Milne (2017) }\end{array}$ & $\begin{array}{l}\text { 1998:M10- 2012:M6 } \\
\text { 13 banka } \\
\text { Birleşik Krallık }\end{array}$ & Havuzlanmış OLS & $\begin{array}{l}\text { Tier } 1 \text { sermaye oranı katsayıları kriz döneminde } \\
\text { pozitiften negatife dönmektedir. }\end{array}$ \\
\hline $\begin{array}{l}\text { Jiménez, Ongena, } \\
\text { Peydró ve Saurina } \\
\text { (2017) }\end{array}$ & $\begin{array}{l}\text { 2002:M2 ve 2010:M12 } \\
\text { 175 Banka } \\
\text { İspanya }\end{array}$ & $\begin{array}{l}\text { Yatay Kesit } \\
\text { Panel Veri Sabit } \\
\text { Etkiler }\end{array}$ & $\begin{array}{l}\text { Konjonktür karşıtı sermaye tamponları kredi } \\
\text { arzı dalgalanmalarını düzleştirmeye yardımcı } \\
\text { olur. }\end{array}$ \\
\hline $\begin{array}{l}\text { Gülenay Chadwick } \\
\text { (2018) }\end{array}$ & 2005:M12 - 2017:M12 & $\begin{array}{l}\text { Araç Değişkenli } \\
\text { Probit Model } \\
\text { Panel VAR }\end{array}$ & $\begin{array}{l}\text { Makro ihtiyati politikalar kredi büyümesi ve oy- } \\
\text { naklığını yavaşlatmakta ve tüketici fiyatları enf- } \\
\text { lasyonunu azaltmakta etkilidir. Bu politikalar } \\
\text { para politikası koordine edildiğinde etki daha } \\
\text { güçlüdür. }\end{array}$ \\
\hline
\end{tabular}

Bu çalışmaların ana vurgusu; kredi talebinin kredi arzı üzerindeki bu etkisinin banka sermayesi etkisinden ayrıştırılmaması nedeniyle banka sermayesinin kredi arzı üzerindeki etkisinin tam olarak belirlenebilmesini engelleyeceği yönündedir. İkinci kategoride sermaye yeterliliklerine ilişkin düzenlemelerin bağlayıcı olup olmadığı tartışması yapılmaktadır. Basel düzenlemeleri kapsamında ya da politika yapıcıların belirlediği oranların bağlayıcı olmadığı durumlarda bu düzenlemelerin etkisi farklı olabilmektedir. Dolayısıyla bankanın gerçekleşen sermaye oranı ve arzu edilen sermaye yeterliliği arasındaki ilişki önem kazanmaktadır. Üçüncü kategoride ise banka sermaye oranı ile banka kredi hacmi arasındaki ilişkinin doğrusal olmadığı yönündeki çaIışmalar yer almaktadır. Buradaki bulgular ise genellikle düşük sermayeli bankaların sermaye yeterliliklerindeki bir sıkılaşmaya kredilerinde sermayesi güçlü olan bankalara göre daha fazla azalma göstererek tepki verebilecekleri yönündedir. Bu çalışmanın literatür taramasında büyük oranda 2008 küresel finansal krizi sonrasında yapılan son dönem çalışmalara yer verilmektedir. Tablo 1'de bu çalışmaların yazarları, veri seti, seçilen örneklem ve yöntemleri ve son olarak ulaşılan sonuçlar genel hatlarıyla özetlenmektedir.

\section{Veri Seti ve Yöntem}

Bankaların sermaye yapısındaki değişmelerin banka varlıklarını özellikle de bu varlıklar içerisinde kredileri nasıl etkilediğini ortaya çıkarabilmek için Türkiye'deki 26 bankanın ${ }^{3} 2002$ ve 2019 arasındaki yılları kapsayan veriler kullanılmıştır. Kullanılan veriler çeyrek dönemliktir ve 2002 yıııın dördüncü çeyreğinden 2019 yılının ikinci çeyreğine kadar toplam 67 dönemi kapsamaktadır. Bankanın sermaye yapısını ya da sermaye yeterlilik oranını temsil etmek amacıyla bankanın toplam öz kaynaklarının bankanın toplam varlıklarına oranı değişkeni kullanılmaktadır. Yine kredi hacmini temsil etmek amacıyla bankanın toplam kredilerinin banka varlıklarına oranı değişkeni kullanılmaktadır. Son olarak banka sermayesinin bir bütün olarak banka varlıkları üzerindeki etkisini gözlemleyebilmek için bankanın toplam varlık büyüklüğü kullanılmaktadır. Hesaplanan bu değişkenlerin hepsinin büyüme oranları kullanılarak modelleme yapılmaktadır.

\footnotetext{
${ }^{3}$ Çalışmaya dâhil edilen bankalar verilerin ulaşılabilirliğine göre seçilmiştir. Bu bankalar şu şekildedir: Akbank T.A.Ş., Alternatifbank A.Ş., Anadolubank A.Ş., Arap Türk Bankası A.Ş., Bank Mellat, Birleşik Fon Bankası A.Ş., Burgan Bank A.Ş., Citibank A.Ş., Denizbank A.Ş., Fibabanka A.Ş., Habib Bank Limited, HSBC Bank A.Ş., ICBC Turkey Bank A.Ş., ING Bank A.Ş., QNB Finansbank A.Ş., Société Générale (SA), Şekerbank T.A.Ş., Turkish Bank A.Ş., Turkland Bank A.Ş., Türk Ekonomi Bankası A.Ş., Türkiye Cumhuriyeti Ziraat Bankası A.Ş., Türkiye Garanti Bankası A.Ş., Türkiye Halk Bankası A.Ş., Türkiye İ̧̧ Bankası A.Ş., Türkiye Vakıflar Bankası T.A.O. ve Yapı ve Kredi Bankası A.Ş.
} 
Çalışmada kullanılan verilerin zaman $T=67$ ve kesit $N=26$ boyutu dikkate alındığında zaman boyutunun yeterince uzun olması yapılacak analizlerde panel zaman serisi modellerinin kullanılmasını gerekli kılmaktadır. Bu sebeple çalışmada tercih edilen yöntem panel VAR olarak belirlenmektedir ${ }^{4}$. Bu yöntem sistemdeki tüm değişkenlerin içsel olduğu geleneksel zaman serisi VAR yaklaşımı ile gözlemlenemeyen bireysel heterojenliğe imkân veren panel veriyi birleştirmektedir. Love ve Zicchino (2006) takip edilerek oluşturulan panel VAR ekonometrik modelinin genel formu aşağıdaki gibi ifade edilebilir:

$X_{i t}=\Gamma_{0}+\Gamma_{1} X_{i t-1}+u_{i}+\epsilon_{i t}, \quad i=1, \ldots, N$ ve $t=1, \ldots, T$

Burada $X_{i t}$ durağan değişkenlerin bir vektörüdür. Bu değişkenler sırasıyla sermayenin varlıklar içindeki payının büyüme oranı, kredilerin varlıklar içindeki payının büyüme oranı ve varlıkların büyüme oranı şeklindedir ${ }^{5} . \Gamma_{0}$, sabit terim vektörü ve $\Gamma_{1}$, katsayı matrisidir. $u_{i}$, bankaya özgü etkileri diğer bir ifadeyle sabit etkileri gösterirken, $\epsilon_{i t}$ ise hata terimi vektörüdür. Sabit etkilerin varlığı bağımlı değişkenin gecikmeli değerlerini içeren dinamik panellerde sapmalı ve tutarsız sonuçlara yol açmaktadır. Çünkü sabit etkiler açıklayıcı değişkenler ile korelasyona sahiptir. Dolayısıyla bu problemi ortadan kaldırmak için genellikle "Helmert yöntemi" olarak bilinen ileriye dönük ortalama farklar tekniği kullanılmaktadır (Arellano ve Bover, 1995). Bu dönüşüm sonrasında sistem GMM modeli katsayılarını tahmin etmek için açıklayıcı değişkenlerin gecikmeli değerleri araç değişken olarak kullanılabilir (Love ve Zicchino, 2006). Denklem (1)'deki panel VAR modeli tahmin edildikten sonra sistemdeki içsel değişkenlerde ortaya çıkan bir şokun diğer değişkenler üzerindeki etkisini, etki tepki fonksiyonları aracılığıyla gözlemleyebiliriz. Elde edilen etki tepki fonksiyonlarına ait güven aralıkları Monte-Carlo simülasyonları kullanılarak oluşturulmaktadır.

\section{Ekonometrik Modelleme ve Bulgular}

Panel zaman serisi modelinin ilk aşamasında verilerin panel birimler arasında yatay kesit bağımlılığı içerip içermediğine bakılmaktadır. Yatay kesit bağımlılı̆ının incelenmesinin ardındaki gerekçe, kesitlerin birini etkileyen şokların aynı zamanda diğer kesiti de etkileyebilmesi varsayımıdır. Pesaran (2006)'ın Monte Carlo deneyleri sonuçlarına göre, bir panel veri çalışmasında yatay kesit bağımlıığının dikkate alınmaması önemli ölçüde sapmalara yol açmaktadır.

Tablo 2. Yatay-kesit Bağımlılı̆ı Testleri

\begin{tabular}{|c|c|c|c|c|c|c|}
\hline \multirow[t]{2}{*}{ Sabitli Model } & \multicolumn{2}{|c|}{$\begin{array}{c}\text { (Krediler/Varlıklar) } \\
\text { Büyüme Oranı }\end{array}$} & \multicolumn{2}{|c|}{$\begin{array}{l}\text { Varlıkların } \\
\text { Büyüme Oranı }\end{array}$} & \multicolumn{2}{|c|}{$\begin{array}{l}\text { (Sermaye/Varlıklar) } \\
\text { Büyüme Oranı }\end{array}$} \\
\hline & $\begin{array}{c}\text { Test } \\
\text { İstatistiği }\end{array}$ & $\begin{array}{c}p \\
\text { değeri }\end{array}$ & $\begin{array}{c}\text { Test } \\
\text { İstatistiği }\end{array}$ & $\begin{array}{c}p \\
\text { değeri } \\
\end{array}$ & $\begin{array}{c}\text { Test } \\
\text { İstatistiği }\end{array}$ & $\begin{array}{c}p \\
\text { değeri }\end{array}$ \\
\hline$C D_{l m} \quad(\mathrm{BP}, 1980)$ & 796,310 & 0,000 & 757,053 & 0,000 & 564,984 & 0,000 \\
\hline$C D_{l m}$ (Pesaran, 2004) & 18,486 & 0,000 & 16,947 & 0,000 & 9,413 & 0,000 \\
\hline$C D \quad$ (Pesaran, 2004) & 13,265 & 0,000 & 4,044 & 0,000 & $-0,290$ & 0,386 \\
\hline$L M_{a d j}(\mathrm{PUY}, 2008)$ & 2,634 & 0,004 & 14,501 & 0,000 & 7,059 & 0,000 \\
\hline
\end{tabular}

Yatay kesit bağımlılığının varlığını incelemek için sırasıyla Breusch ve Pagan (1980), Pesaran (2004) ve Pesaran vd., (2008) tarafından geliştirilen dört farklı testin sonuçları Tablo 2'de gösterilmektedir. Açık bir şekilde görüldüğü üzere $C D$ testinin sermayenin aktif büyüklüğe oranının

\footnotetext{
${ }^{4}$ Panel VAR modelinin tercih edilmesine yönelik aşamalar bir sonraki bölümde anlatılmaktadır.

${ }^{5}$ Değişkenlerin sıralaması değiştirildiğinde elde edilen sonuçlar birbirine oldukça yakındır. Dolayısıyla burada alternatif sıralamalara ilişkin bulgular rapor edilmemektedir.
} 
büyüme oranı değişkenine ilişkin sonuç dışındaki tüm testler ve değişkenler için yatay kesit bağımlılı̆ının varlığını belirten boş hipotez güçlü bir biçimde reddedilmektedir. CD testi büyük N ve küçük T değerleri için daha tutarlı sonuçlar vermektedir. Çalışmanın örneklemi dikkate alındığında ( $T>N$ ) diğer testlerin sonuçlarına güvenilebileceği ve dolayısıyla değişkenlerin hepsinin yatay kesit bağımlılığına sahip olduğu söylenebilir. Yatay kesit bağımlılığının varlığı değişkenlere ilişkin durağanlık sınamalarında kullanılacak birim kök testlerinin seçimini etkilemektedir. Yatay kesit bağımlılığının varlığı nedeniyle durağanlık sınaması için yatay kesit bağımlılı̆̆ını dikkate alan ikinci nesil birim kök testleri kullanılmaktadır.

İkinci aşamada değişkenlerin durağanlıklarını test etmek amacıyla yatay kesit bağımlılığını hesaba katan üç farklı birim kök testinin sonucu değerlendirilmektedir. Tablo 3 Pesaran (2007) tarafından geliştirilen CADF birim kök testi sonuçlarını göstermektedir. Sonuçlar hem sabitli hem de sabit ve trendli modellere göre tüm değişkenler için serilerin birim kök içerdiği şeklindeki boş hipotezin reddedildiğini ifade etmektedir. Dolayısıyla CADF testi sonuçları tüm değişkenlerin düzeyde I(0) durağan olduğu yönündedir. Kullanılan ikinci birim kök testi Smith vd. (2004) tarafından geliştirilmiştir ve sonuçları Tablo 4'te yer almaktadır. Bootstraplı olasılık değerleri hem sabitli hem de sabit ve trendli modelde serilerin düzey değerlerinde durağan olduklarını göstermektedir. Birim kök sınaması için kullanılan son test ise Bai ve Ng (2004) tarafından geliştirilen PANIC birim kök testidir. Bu teste ait sonuçlar ise Tablo 5'te yer almaktadır. Yine burada da diğer testlerde olduğu gibi her bir değişken için her iki modelde de birim kökün varlığı doğrulanamamaktadır.

Tablo 3. Pesaran CADF Birim Kök Testi

\begin{tabular}{|c|c|c|c|c|c|c|}
\hline \multirow{3}{*}{ Değişkenlerin Düzey değerleri } & \multicolumn{6}{|c|}{ Sabit Terim } \\
\hline & \multirow[b]{2}{*}{ t-bar } & \multicolumn{3}{|c|}{ Kritik Değerler } & \multirow[b]{2}{*}{$\mathrm{Z}[\mathrm{t}-\mathrm{b} a r]$} & \multirow[b]{2}{*}{ p-değeri } \\
\hline & & $\% 10$ & $\% 5$ & $\% 1$ & & \\
\hline $\begin{array}{l}\text { (Krediler/Varlıklar) } \\
\text { Büyüme Oranı }\end{array}$ & $-3,700$ & $-2,080$ & $-2,150$ & $-2,300$ & $-10,639$ & 0,000 \\
\hline Varlıkların Büyüme Oranı & $-3,108$ & $-2,080$ & $-2,150$ & $-2,300$ & $-7,358$ & 0,000 \\
\hline \multirow[t]{2}{*}{ Büyüme Oranı } & $-3,258$ & $-2,080$ & $-2,150$ & $-2,300$ & $-8,189$ & 0,000 \\
\hline & \multicolumn{6}{|c|}{ Sabit Terim ve Trend } \\
\hline $\begin{array}{l}\text { (Krediler/Varlıklar) } \\
\text { Büyüme Oranı }\end{array}$ & $-4,252$ & $-2,580$ & $-2,650$ & $-2,780$ & $-11,336$ & 0,000 \\
\hline Varlıkların Büyüme Oranı & $-3,233$ & $-2,580$ & $-2,650$ & $-2,780$ & $-5,296$ & 0,000 \\
\hline $\begin{array}{l}\text { (Sermaye/Varlıklar) } \\
\text { Büyüme Oranı }\end{array}$ & $-3,409$ & $-2,580$ & $-2,650$ & $-2,780$ & $-6,340$ & 0,000 \\
\hline
\end{tabular}

Tablo 4. Smith vd. (2004) "bootstrap" Panel Birim Kök Testleri

\begin{tabular}{|c|c|c|c|c|}
\hline \multirow{2}{*}{ Değişkenlerin Düzey Değerleri } & \multicolumn{2}{|c|}{ Sabit } & \multicolumn{2}{|c|}{ Sabit ve Trend } \\
\hline & Tot ictictič & Bootstrap & Toctictotictǐ̌ & Bootstrap \\
\hline \multicolumn{5}{|l|}{ (Krediler/Varlıklar) Büyüme Oranı } \\
\hline$t-b a r$ & $-7,228$ & 0,000 & $-7,179$ & 0,000 \\
\hline WS & $-7,092$ & 0,000 & $-6,991$ & 0,000 \\
\hline \multicolumn{5}{|l|}{ Varlıkların Büyüme Oranı } \\
\hline$t$-bar & $-7,544$ & 0,000 & $-7,483$ & 0,000 \\
\hline WS & $-7,478$ & 0,000 & $-7,399$ & 0,000 \\
\hline \multicolumn{5}{|l|}{ (Sermaye/Varlıklar) Büyüme Oranı } \\
\hline$t-b a r$ & $-8,299$ & 0,000 & $-8,250$ & 0,000 \\
\hline WS & $-8,304$ & 0,000 & $-8,305$ & 0,000 \\
\hline
\end{tabular}

Not: Maksimum gecikme uzunluğu 4 olarak alınmış ve optimal gecikme uzunlukları genelden özele (general-to-specific) yaklaşımı ile belirlenmiştir. Olasılık değerleri 10000 bootstrap dağılımından elde edilmiştir. 
Yatay kesit bağımlılığını dikkate alan birim kök testlerinden elde edilen ortak sonuç çalışmada kullanılan değişkenlerin hepsinin düzey değerlerinde durağan yani I(0) olduğu şeklindedir. Kullanılan değişkenlerin ampirik özellikleri, durağan değişkenler ile bir panel VAR modeli kurulabilmesine imkan vermektedir. Bu kısımda Panel VAR modelinden elde edilen etki tepki fonksiyonlarına ve varyans ayrıştırmasına yer verilmektedir. Panel VAR modeli kurulurken gecikme uzunluğunun seçimi önem arz etmektedir. Gecikme uzunluğunun fazla kısa olması ihmal edilmiş değişken sorunlarına yol açabilirken gecikme uzunluğunun fazla uzun seçilmesi ise serbestlik derecesi kayıpları ve aşırı parametre tahminlerine yol açabilmektedir. Panel VAR modelinin optimal gecikme uzunluğu Hansen (1982) J-istatistiğine dayanan GMM modelleri için Andrews ve Lu (2001) tarafından önerilen model seçim kriterleri dikkate alındığında 2 olarak seçilmektedir. Tahmin edilen panel VAR modelinde kökler birim çemberin içinde yer almaktadır dolayısıyla model istikrarlıdır.

Tablo 5. PANIC Panel Birim Kök Testleri

\begin{tabular}{|c|c|c|c|c|}
\hline \multirow{2}{*}{ Değişkenlerin Düzey Değerleri } & \multicolumn{2}{|c|}{ Sabit } & \multicolumn{2}{|c|}{ Sabit ve Trend } \\
\hline & Test İstatistiği & p-değeri & Test İstatistiği & p-değeri \\
\hline \multicolumn{5}{|l|}{ (Krediler/Varlıklar) Büyüme Oranı } \\
\hline$Z_{\hat{e}}^{c}$ & 13,859 & 0,000 & 13,669 & 0,000 \\
\hline$P_{\hat{e}}^{c}$ & 193,315 & 0,000 & 191,399 & 0,000 \\
\hline \multicolumn{5}{|l|}{ Varlıkların Büyüme Oranı } \\
\hline$Z_{\hat{e}}^{c}$ & 13,916 & 0,000 & 14,324 & 0,000 \\
\hline$P_{\hat{e}}^{c}$ & 193,917 & 0,000 & 198,085 & 0,000 \\
\hline \multicolumn{5}{|l|}{ (Sermaye/Varlıklar) Büyüme Oranı } \\
\hline$Z_{\hat{e}}^{c}$ & 15,297 & 0,000 & 15,297 & 0,000 \\
\hline$P_{\hat{e}}^{c}$ & 208,000 & 0,000 & 208,000 & 0,000 \\
\hline
\end{tabular}

Şekil 1-6 Panel VAR modeline dayanan ve her bir içsel değişkendeki bir standart sapmalık şok karşısında diğer değişkenlerin ne kadar tepki verdiğini ifade eden etki tepki fonksiyonlarını göstermektedir. Tüm grafikler şok sonrasındaki 10 dönem (çeyrek) için tahmin edilmektedir. Gri gölgeli alanlar \%95 güven aralıklarını temsil etmektedir. Bu güven aralıkları 1000 bootstrap sonucu elde edilmektedir. Değişkenlerin herhangi birinde yaşanan bir şok sonrasında diğer değişkenlerin tümünün tepkisi 10 dönem dolmadan önce sonlanmakta ve sıfıra yakınsamaktadır.

Şekil 1 ve 2 banka varlıklarında ortaya çıkan pozitif bir şoka sırasıyla banka kredilerinin ve banka varlıklarının nasıl tepki verdiğini göstermektedir. Banka varlıklarındaki bir pozitif bir şokun banka kredileri üzerindeki etkisi belirgin değildir. Banka kredileri değişkeni, banka kredilerinin banka varlıklarına oranındaki artıştan oluşmaktadır. Dolayısıyla banka varlıklarındaki bir şokun banka kredileri ve diğer varlık kalemleri arasında eşit bir şekilde etki gösterdiği düşünülebilir. Banka kredileri ve diğer varlık kalemlerinde aynı oranda artışların bu değişkenin tepki vermemesine yol açabilir. Banka varlıklarına banka sermayesinin verdiği tepki ise pozitif ve anlamlıdır. Ancak bu tepki bir dönemde maksimuma ulaşırken ikinci dönemin sonunda ise kaybolmaktadır.

\footnotetext{
${ }^{6}$ Panel VAR modelinin istikrarlı olduğuna dair bu bulgu çalışmada rapor edilmemektedir ancak istenildiği takdirde yazar tarafından temin edilebilir.
} 


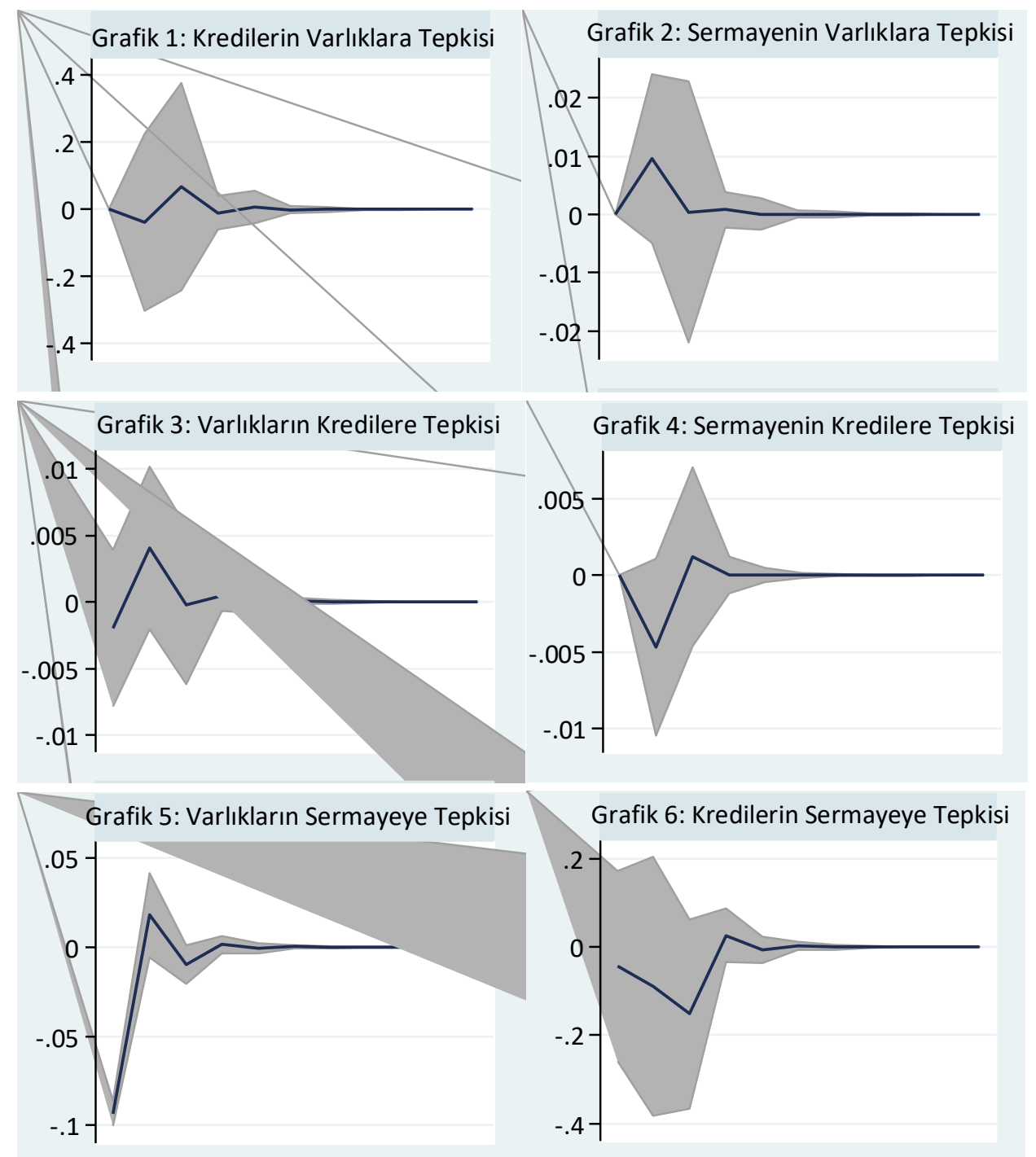

Not: Panel VAR modelinin en uygun gecikme uzunluğu 2 olarak belirlenmektedir. Modelde verilen şoklar Choleski ayrıştırmasından türetilmekte ve 10 dönem ileriye gitmektedir. Panel VAR modelinde değişkenlerin sıralaması sermayenin varlıkların içindeki payının büyüme oranı, kredilerin varlıklar içindeki payının büyüme oranı ve varlıkların büyüme oranı şeklindedir.

Şekil 2 ve 3 banka kredilerindeki pozitif bir şoka sırasıyla banka varlıkları ve sermayesinin nasıl tepki verdiğini göstermektedir. Banka varlıkları ve sermayesinin her ikisinin tepkisi de üçüncü dönemin sonunda sıfıra inerken banka sermayesinin tepkisi daima negatif ve anlamlıdır. Ancak banka varlıkları ise bu şoka önce negatif tepki verirken bir dönem sonra bu tepki pozitife dönmektedir. Banka kredilerindeki şokların banka varlıklarının büyüme oranını geçici olarak yavaşlatması şu şekilde ortaya çıkabilir. Ekonominin genişleme dönemlerinde artan kredi talepleri karşısında bankalar bu talepleri karşılayacak yeterli kaynaklardan yoksunsa karlı kredi fırsatlarını geri çevirmemek için diğer varlıklarını kredilere dönüştürebilir. Böylesi bir varlık dönüşümü başlangıçta banka aktif büyüklüğünü etkilemeyebilir ancak artan kredi talebiyle birlikte 
faizlerdeki yükseliş bankanın mevduat cinsinden kaynak yaratmasını ve bu kaynakları diğer varlıklara ya da kredilere plase etmesini kolaylaştırabilir. Bu ikinci gelişme ise bankanın aktif büyüklüğünün artmasını beraberinde getirecektir. Banka kredilerinin banka varlıklarına oranındaki bir şoka banka sermayesinin banka varlıklarına oranının azalarak tepki vermesi ise varlıklar büyürken banka sermayesinin aynı oranda büyümediğini göstermekte ve dolayısıyla bankanın sermaye varlık oranının azalmasına yol açmaktadır. Bu bulgu bankaların ekonominin genişleme dönemlerinde özellikle kredi talebinde sert bir artış meydana geldiğinde ve bu talebi karşılamak istediklerinde sermaye oranlarını geçici olarak gevşetebildikleri ya da uyarlamakta zorlandıkları şeklinde değerlendirilebilir.

Şekil 5 ve 6 ise bankaların sermaye oranlarındaki pozitif bir şokun sırasıyla banka varlıklarını ve banka kredilerini nasıl etkilediğini göstermektedir. Banka varlıkları ve kredilerinin her ikisi de bu şoka negatif ve anlamlı tepkiler vermekte diğer yandan banka sermaye şoklarının varlıklar üzerindeki etkisi üç dönem sürerken bu şoka kredilerin tepkisi ise dört dönem sonra sona ermektedir. Banka kredilerinin banka sermayesine tepkisi tüm etki tepki fonksiyonları içinde en ısrarcı olanıdır. Bankaların sermayesinin banka varlıklarına oranındaki pozitif bir şok karşısında ki, bu politika yapıcılar tarafından zorlayıcı bir gelişme şeklinde de olabilir, bankaların ya sermayelerini artırmalarını ya da varlıklarını azaltmalarını gerekli kılmaktadır. Elde edilen bu sınırlı bulgular sermaye varlık oranlarındaki bir artış karşısında Türkiye'deki bankaların ilk olarak varlıklarını azaltarak tepki verdilerini göstermektedir. Diğer taraftan böyle bir şok karşısında kredilerin varlıklara oranındaki artışlar yavaşlamaktadır. Bu durum ancak kredilerin varlıklardan daha hızlı azaldığı azalan bir varlık büyümesi durumunda söz konusu olabilir. Dolayısıyla bankalar sermaye yeterliliklerinde bir artışı büyük ölçüde kredi büyümesini yavaşlatarak diğer bir ifadeyle kredilerini azaltarak sağlayabilmektedirler. Bu bulgular bankaların sermaye yapısı üzerinde etki yaratabilecek türdeki makro ihtiyati politikalar karşısında banka kredilerinin örtülü bir şekilde diğer banka varlıklarına göre daha hassas olduğunu ima etmektedir.

Çalışmada Türkiye için elde edilen etki tepki fonksiyonlarına dayalı bu bulguların çoğu diğer ülke örneklerinin incelendiği Drehmann ve Gambacorta (2012), Francis ve Osborne (2012), Jiménez, vd. (2012), Maurin ve Toivanen (2012), Aiyar, vd. (2014), Karmakar ve Mok (2015) çalışmaları ile karşılaştırıldığında benzerlik göstermektedir. Bunun yanı sıra sonuçlar makro ihtiyati politikaların kredi büyümesi üzerindeki etkilerini Türkiye için araştıran Gülenay Chadwick (2018) çalışmasının bulgularını destekler niteliktedir.

\section{Sonuç ve Politika Önerileri}

Son otuz yılda gelişmiş ve gelişmekte olan ülkelerin neredeyse hepsinde finansal sistem bir bütün olarak hızlı bir gelişme göstermiştir. Finansal sistemin diğer unsurları gelişmeye devam ediyor olmakla birlikte bankacılık sektörü hala gelişmekte olan ülkelerde finansal yapının ana omurgasını oluşturmaktadır. Dolayısıyla bu ülkelerde finansal sistemin istikrarı büyük oranda bankacılık sektörünün istikrarlı ve iyi işleyen bir yapıya sahip olmasına bağlıdır. Bu durum Türkiye içinde istisna değildir. 2001 yılında yaşanan bankacılık sektörü kaynaklı krizden itibaren bankacılık sektörüne ve sermaye yapısına ilişkin düzenlemeler politika yapıcıların gündeminde yer almaktadır. Meselenin politika kısmında bakış açısı daha belirgin olmasına rağmen bu politikaların finansal istikrar üzerindeki etkisinin neler olabileceği konusu akademik literatürde tartışılmaya devam etmektedir. Dolayısıyla bu çalışmadaki temel motivasyon son yıllarda ortaya çıkan bu gelişmeler çerçevesinde tasarlanan sermaye yeterlilikleri ya da sermaye tamponları gibi bankaların sermaye yapısına ilişkin makro ihtiyati düzenlemelerin, bankaların varlıkları özel- 
likle de kredi hacmi üzerinde yaratabileceği etkileri incelemektir. Bu çerçevede Türkiye'de faaliyet gösteren 26 bankaya ait 2002 ve 2019 yılları arası çeyreklik veriler ile Panel VAR ekonometrik modeli kullanılmaktadır. Elde edilen bulgular bankaların sermayesinde yaşanan pozitif bir şok karşısında varlıklarını azaltarak tepki verdikleri yönündedir. Daha da önemlisi varıkklar içinde kredilerin verdiği tepkinin diğer varlık kalemlerinden daha fazla olduğu sonucuna varılmaktadır. Bu sonuç banka kredilerinin banka sermayesindeki değişimlere diğer banka varlıklarına göre daha duyarlı olduğunu göstermektedir. Bu sonuçlar bankaların sermaye yeterlilikleri ya da sermaye tamponları gibi sermaye yapısına ilişkin politika araçlarındaki sıkılaşmaların aşırı kredi genişlemesini yavaşlatmakta ve kredi dalgalanmalarını dolayısıyla da iktisadi dalgalanmaları azaltmakta kullanılabileceği şeklinde yorumlanabilir. Ancak çalışmanın bu bulgularının dikkatli bir biçimde yorumlanması gerekmektedir. Bu sonuçlar sermaye yapısına ilişkin araçların konjonktürel tasarımının etkinliği konusunda tam olarak bir şey söylememektedir. Bu araçların konjonktürel olarak tasarlanmasının yaratacağı etkileri ortaya çıkarabilmek için banka sermayesi ve kredi hacmi ilişkisine dair asimetrilerin var olup olmadı̆̆ının incelenmesi gerekmektedir. Bunun yanı sıra literatürde yer alan bu ilişkinin doğrusal olmayabileceğine yönelik şüphelerin de dikkate alınması son derece önemlidir ve bu ilişkinin tespiti ise başka bir araştırmanın konusu olabilir. Diğer yandan politikaların etkinliğine yönelik buradaki en kritik nokta bankanın sermaye oranındaki değiş̧melerin bağlayıcı olup olmadığı konusudur. Bankaların sermaye oranları, düzenleyici otoritenin belirlediği düzeyin altında ya da üstünde olduğu durumlarda bu politikaların etkinliği farklılaşabilir. Dolayısıyla politika tasarımı sırasında bankaların sermaye durumları tek tek incelenmeli fakat politikanın krediler üzerindeki etkileri bütüncül olarak ele alınmalıdır. Bir diğer vurgulanması gereken nokta ise bu çalışmanın sermaye yapısına daha genel yaklaşmış olmasıdır. Dolayısıyla gelecek çalışmalarda daha farklı ya da Basel III kapsamında belirlenen daha formel sermaye yeterlilik oranları değişkenleri hesaplanarak sermaye yapısındaki daha spesifik değişmelerin banka varlıkları, kredileri ya da banka performansı üzerindeki etkilerinin daha detaylı bir biçimde ortaya çıkarılması bu ilişkiye dair bilgilerimizi artırabilir. Son olarak banka sermaye yapısındaki değişmelere hangi kredi türünün daha duyarlı olduğu bilgisi bu politikaların tasarımı sırasında önemli bir bilgi olabilir. Şüphesiz ki sonraki çalışmalar farklı kredi türleri ile banka sermayesi arasındaki ilişkileri inceleyerek bu konu hakkında daha detaylı bulgular elde etmesi politika yapıcılara daha iyi bir yol gösterici olabilir. 


\section{Eskişehir Osmangazi Üniversitesi IïB Dergisi}

\section{Kaynaklar}

Adrian, Tobias; Shin, Hyun Song (2010), "Liquidity and leverage”, Journal of financial intermediation, Vol. 19 No. 3: 418437.

Aiyar, Shekhar; Calomiris, Charles W.; Wieladek, Tomasz (2014), “Does macro-prudential regulation leak? Evidence from a UK policy experiment", Journal of Money, Credit and Banking, Vol. 46: 181-214.

Andrews, Donald WK; Lu, Biao (2001), "Consistent model and moment selection procedures for GMM estimation with application to dynamic panel data models", Journal of Econometrics, Vol. 101 No. 1: 123-164.

Arellano, Manuel; Bover, Olympia (1995), "Another look at the instrumental variable estimation of error-components models", Journal of econometrics, Vol. 68 No. 1: 29-51.

Bai, Jushan; Ng, Serena (2004), “A PANIC attack on unit roots and cointegration”, Econometrica, Vol. 72 No. 4: 11271177.

Berger, Allen N.; Bouwman, Christa HS. (2013), “How does capital affect bank performance during financial crises?”, Journal of Financial Economics, Vol. 109 No. 1: 146-176.

Berger, Allen N.; Udell, Gregory F. (1994), "Did risk-based capital allocate bank credit and cause a" credit crunch" in the United States?”, Journal of Money, credit and Banking, Vol. 26 No. 3: 585-628.

Berrospide, Jose M.; Rochelle M. Edge (2010), "The Effects of Bank Capital on Lending: What Do We Know, and What Does It Mean?", International Journal of Central Banking, Vol. 6 No. 34: 1-50.

Breusch, Trevor S.; Pagan, Adrian R. (1980), "The Lagrange multiplier test and its applications to model specification in econometrics", The review of economic studies, Vol. 47 No. 1: 239-253.

Carlson, Mark; Shan, Hui; Warusawitharana, Missaka (2013), "Capital ratios and bank lending: A matched bank approach", Journal of Financial Intermediation, Vol. 22 No. 4: 663-687.

Chadwick, Meltem Gülenay (2018), "Effectiveness of monetary and macroprudential shocks on consumer credit growth and volatility in Turkey", Central Bank Review, Vol. 18 No. 2: 69-83.

Dewatripont, Mathias; Tirole, Jean (1994), "A theory of debt and equity: Diversity of securities and manager-shareholder congruence", The quarterly journal of economics, Vol. 109 No. 4: 1027-1054.

Drehmann, Mathias; Gambacorta, Leonardo (2012), "The effects of countercyclical capital buffers on bank lending", Applied economics letters, Vol. 19 No. 7: 603-608.

Elliott, Douglas J. (2009), "Quantifying the effects on lending of increased capital requirements", The Brookings Institution. http://centerforfinancialstability.net/forum/elliott_increased_capital_requirements_200909.pdf (Erişim: 11.10.2016).

Francis, William B.; Osborne, Matthew (2012), "Capital requirements and bank behavior in the UK: Are there lessons for international capital standards?", Journal of Banking \& Finance, Vol. 36 No. 3: 803-816.

Gambacorta, Leonardo; Mistrulli, Paolo Emilio (2004), “Does bank capital affect lending behavior?”, Journal of Financial Intermediation, Vol. 13 No. 4: 436-457.

Hancock, Diana; Wilcox, James A. (1994), "Bank capital and the credit crunch: The roles of risk-weighted and unweighted capital regulations", Real Estate Economics, Vol. 22 No. 1: 59-94.

Hansen, Lars Peter (1982), "Large sample properties of generalized method of moments estimators", Econometrica, Vol. 50 No. 4: 1029-1054.

Jiménez, Gabriel; Ongena, Steven; Peydró, José-Luis; Saurina, Jesús (2017), “Macroprudential policy, countercyclical bank capital buffers, and credit supply: evidence from the Spanish dynamic provisioning experiments", Journal of Political Economy, Vol. 125 No. 6: 2126-2177.

Karmakar, Sudipto; Mok, Junghwan (2015), "Bank capital and lending: An analysis of commercial banks in the United States", Economics Letters, Vol. 128 No. 3: 21-24.

Košak, Marko; Li, Shaofang; Lončarski, Igor; Marinč, Matej (2015), “Quality of bank capital and bank lending behavior during the global financial crisis", International review of financial analysis, Vol. 37: 168-183.

Labonne, Claire; Lamé, Gildas (2014), “Credit Growth and Bank Capital Requirements: Binding or Not?”, Banque de France, No. 481.

Love, Inessa; Zicchino, Lea (2006), "Financial development and dynamic investment behavior: Evidence from panel VAR", The Quarterly Review of Economics and Finance, Vol. 46 No. 2: 190-210. 
Maurin, Laurent; Toivanen, Mervi (2012), “Risk, capital buffer and bank lending: a granular approach to the adjustment of euro area banks", European Central Bank, No. 1499.

Miller, M., \& Modigliani, F. (1958), "The Cost of capital, corporate finance and the theory of investment", American Economic Review, Vol. 48 No. 3: 261-297.

Mora, Nada; Logan, Andrew (2012), "Shocks to bank capital: evidence from UK banks at home and away", Applied Economics, Vol. 44 No. 9: 1103-1119.

Nier, Erlend; Zicchino, Lea (2005), "Bank weakness and bank loan supply", Bank of England Financial Stability Review, 85-93.

Osborne, Matthew; Fuertes, Ana-Maria; Milne, Alistair (2017), "In good times and in bad: Bank capital ratios and lending rates", International Review of Financial Analysis, Vol. 51, 102-112.

Peek, Joe; Rosengren, Eric (1995), "The capital crunch: Neither a borrower nor a lender be", Journal of Money, Credit and Banking, Vol. 27 No. 3: 625-638.

Pesaran, M. Hashem (2007), "A simple panel unit root test in the presence of cross-section dependence", Journal of Applied Econometrics, Vol. 22 No. 2: 265-312.

Pesaran, M. Hashem (2004), "General Diagnostic Tests for Cross Section Dependence in Panels", CESifo Working Paper, No. 1229, Institute for the Study of Labor (IZA) Discussion Paper, No. 1240.

Pesaran, M. Hashem (2006), "Estimation and inference in large heterogeneous panel with a multifactor error structure", Econometrica Vol. 74 No. 4: 967-1012.

Pesaran, M. Hashem; Ullah, Aman; Yamagata, Takashi A. (2008), “A Bias-adjusted LM Test of Error Cross-Section Independence", Econometrics Journal, Vol. 11 No. 1: 105-127.

Smith Vanessa; Leybourne, Stephen; Kim, Tae Hwan; Newbold, Paul (2004), "More powerful Panel Data Unit Root Tests With An Application To Mean Reversion İn Real Exchange Rates", Journal of Applied Econometrics, Vol. 19 No. 2: 147-170.

Tabak, Benjamin M.; Noronha, Ana Clara BTF; Cajueiro, Daniel O. (2011), "Bank capital buffers, lending growth and economic cycle: empirical evidence for Brazil", In 2nd BIS CCA Conference on "Monetary policy, financial stability and the business cycle", 12-13 May.

Van den Heuvel, Skander J. (2002), "The bank capital channel of monetary policy", The Wharton School, University of Pennsylvania, mimeo, 2013-14.

VanHoose, David (2007), "Theories of bank behavior under capital regulation", Journal of Banking \& Finance, Vol. 31 No. 12: 3680-3697. 


\section{Extended Summary}

\section{Bank Capital Shocks and Credit Growth: Turkish Banking Sector}

Regulations on the capital structure of banks have become an essential part of countries' macroeconomic policies in recent years. The sharp losses in the assets of banks and financial institutions, especially during the 2008-2009 global financial crisis, led to the deterioration in the capital structure of these institutions. These events have further emphasized the importance of regulations regarding the capital structure of banks. In this framework, cyclical capital adequacy ratios have been used as a new macroprudential policy tool by policymakers. Although these practices are used on the policy side, the potential effects of policy instruments such as capital adequacy ratios or capital buffers regarding the capital structure need to be more clearly revealed. The most basic question that comes to mind here is how banks' loans react to the fluctuations that occur in the banks' capital or the ratio of their capital to their assets. The answer to this question is theoretically and empirically not clear. This study aims to empirically contribute to the debate on how bank loans react to shocks in bank capital with Turkey data.

Most of the theoretical and empirical literature on how bank capital affects bank loans proceeds by relaxing the standard assumptions of the Modigliani and Miller (1958) theorem (Hancock ve Wilcox, 1994; Berger ve Udell, 1994; Peek ve Rosengren, 1995; Van den Heuvel, 2002; Gambacorta ve Mistrulli, 2004; Nier ve Zicchino, 2005; Berrospide ve Edge, 2010). If we generally state the results of the Modigliani and Miller theory, banks can provide funds by equity or borrowing to finance their lending opportunities if the conditions of perfect competition in the capital markets are valid. An increase in the rate of equity financing, which is always more costly than borrowing, will be fully offset by the decrease in the unit cost of both debts and equity. Under these conditions, the share of the equity in the funds has no effect on the loan supply. In other words, the capital structure of a bank is unrelated to the bank's value and funding cost (Gambacorta ve Mistrulli, 2004; Elliott, 2009; Francis ve Osborne, 2012; Labonne ve Lamé, 2014). However, this proposition of the theory is valid under idealized conditions. In the real world, the existence of taxes, deposit insurance, and asymmetric information problems can be seen as the main reasons for imperfect competition or market imperfections in the capital markets. The emergence of all these possible factors invalidates this conclusion of the theory and hence reveals that there may be a relationship between the bank's capital structure and loans (Dewatripont ve Tirole, 1994; Elliott, 2009; Labonne ve Lamé, 2014). Another proposition of this theory can be expressed as the cost of equity increases with the leverage ratio. If both proposals are invalid, an increase in equity within the bank's capital structure will deprive the bank of cheaper financing, such as deposits or wholesale funding, thereby leading to a reduction in loans. However, a more realistic framework with market imperfections such as taxes and asymmetric information does not require the second proposition to be invalid as in the first proposition. For example, regardless of whether these market imperfections exist or not, equity costs will increase with the increase in the leverage ratio. Because the bank's risk will increase, and therefore investors who provide funds to the bank will seek higher returns to compensate for this risk. Therefore, an increase in the share of equity within the capital will reduce the marginal cost of equity. Under these conditions, the effect of more capital on loans is uncertain (Labonne ve Lamé, 2014).

To reveal how changes in the capital structure of banks affect bank assets and primarily loans within these assets, we use data covering the periods from 2002 to 2019 of 26 banks in Turkey. The data is quarterly and covers 67 observations from the fourth quarter of 2002 to the second quarter of 2019. In order to represent the capital structure of the bank or the capital adequacy ratio, the ratio of the total equity of the bank to the total assets of the bank is used. Again, to represent the credit volume, the ratio of the bank's total loans to bank assets is used. Finally, the total asset size of the bank is used to observe the effect of bank capital on bank assets. All of these calculated variables are modeled using growth rates. The time dimension of the data is 67 and the cross-section dimension is 26 . The time dimension is sufficiently long, and thus it is necessary to use panel time series models in the analyzes. For this reason, the preferred method in the study is determined as panel VAR.

Findings show that banks react by reducing their assets when a positive shock occurs in their capital. More importantly, it is concluded that the response of loans within assets is stronger than other assets. This result reveals that bank loans are more sensitive to changes in bank capital than other bank assets. We may interpret that the tightening of policy instruments, such as capital adequacy or capital buffers, can slow down excessive credit expansion and reduce credit fluctuations and hence economic fluctuations. However, these findings of the study should be interpreted carefully. These results do not say exactly about the effectiveness of the cyclical design of instruments related to capital structure. In order to reveal the effects of the cyclical design of these tools, it is necessary to examine the relationship between bank capital and loan supply in terms of asymmetries.

On the other hand, the most critical point here regarding the effectiveness of policies is whether the changes in the capital ratio of the bank are binding or not. The effectiveness of these policies may differ when banks' capital ratios are below or above the level set by the regulatory authority. Therefore, the capital structures of the banks should be examined one by one during the policy design, but the effects of the policy on the loans should be considered as a whole. 